\title{
PHENOTYPIC CHARACTERIZATION OF DONKEYS IN BENISHANGUL GUMUZ NATIONAL REGIONAL STATE
}

\author{
Amine MUSTEFA ${ }^{1 \bowtie}$, Abraham ASSEFA ${ }^{1}$, Manaye MISGANAW ${ }^{1}$, Fasil GETACHEW ${ }^{2}$, Solomon \\ ABEGAZ ${ }^{3}$, Abebe HAILU ${ }^{1}$ and Yibrehu EMSHAW ${ }^{1}$ \\ 1Ethiopian Biodiversity Institute, P. O. Box 30726, Addis Ababa, Ethiopia \\ 2ILRI (International Livestock Research Institute), P. O. Box 5689, Addis Ababa, Ethiopia \\ ${ }^{3}$ EIAR (Ethiopian Institute of Agricultural Research, Debre-Zeit Agricultural Research Center), P. O. Box Bishoftu, Ethiopia \\ Email: aminemustefa32@gmail.com; (D) ORCiD: 0000-0003-3788-4156 \\ Supporting Information
}

\begin{abstract}
Fifteen morphometric measurements and eighteen qualitative traits were recorded on 323 randomly sampled adult donkeys (123 jacks and 200 jennets) to meet an objective of characterizing a heterogeneous donkey population of three phenotypic types (Sinnar, the locals and their crosses) found in Benishangul Gumuz region of Ethiopia. The General Linear Model and non-parametric test (chi-square) procedures of SAS software were used for the analysis of the morphometric data and qualitative traits, respectively. Means were separated using the Tukey-Kramer test. The studied morphometric measurements were significantly affected by the phenotypic type and partially affected by sex and sample location /district. Sinnar donkeys were significantly bigger and heavier than the local and the crosses. However, for some of the morphometric measurements no significance difference was observed between Sinnar and crosses implying the presence of heterosis. Heart girth measurements for Sinnar, local and crosses were 110.61 \pm 0.436 , $106.18 \pm 0.448$ and $108.87 \pm 1.251$, respectively. Body weight estimates of $127.26 \pm 1.277,113.40 \pm 1.312$ and $121.13 \pm 3.665 \mathrm{~kg}$ were obtained for Sinnar, the local and the crosses. There was sexual size dimorphism and depending on the type of morphometric trait either jacks or jennets show significantly $(P<0.05)$ higher values as compared to the opposite sex. Jacks had wider chest (22.61 vs $22.09 \mathrm{~cm}$.), thicker $(24.40 \mathrm{vs} 23.24 \mathrm{~cm}$.), and longer cannon bone $(31.00$ vs $31.32 \mathrm{~cm})$ than jennets, while the jennets possess wider hip (33.00 vs $31.69 \mathrm{~cm}$.) and longer body ( $90.49 \mathrm{vs} 88.52 \mathrm{~cm}$.), back (67.37 vs 66.17$)$, ear (24.42 vs $23.90 \mathrm{~cm})$ and heavier estimated weight $(\mathbf{1 2 2 . 4 7}$ vs $118.71 \mathrm{~kg})$ than the jacks. Limited location effect was recorded showing donkeys from Guba district were comparatively the largest. Majority of the studied donkeys possess white abdominal color, unpigmented hoof and muzzle, short and medium hair size, plain body color pattern with long dorsal stripe without leg stripe, straight face and sloppy rump profile, medium tail length and thickness at the base of the tail. Qualitative differences $(P<0.05)$ were also observed among the class categories. Further molecular level studies could supplement the current study and provide more refined classification of the various genotypes in the studied area. Similarly, characterization of the local donkeys found in other parts of the region and the Abyssinian donkeys in the adjoining areas is required.
\end{abstract}

Keywords: Heart girth, Morphometric, Qualitative, Phenotypic types, Sinnar

\section{INTRODUCTION}

Ethiopia is endowed with diverse domestic, aquatic and wild animal genetic resources. The diverse ecology Ethiopia has and its position as a route of entry to domestic animals from Asia to Africa has resulted in the presence of diverse animal genetic resources. Despite the presence of the resources adequate characterization work is lacking and the information on the state of the animal genetic resources is incomplete to support sustainable utilization and conservation of the resources (EBI, 2016). This is more so for the equine genetic resources of the country.

Donkeys, like other livestock species, have an important place in rural and urban communities in Ethiopia. Even if donkeys have not been serving as a food source to humans in Ethiopia due to religious and cultural taboos, they make significant economic contribution in all the regions. Donkeys specifically are important for transport of goods in urban, peri-urban and rural areas. In the latter case they also serve in transporting humans, threshing cereal crops and plowing of land pairing with oxen.

The donkey (Equus asinus) is indigenous to the African continent and its wild progenitor is usually considered to be the Nubian wild ass (Blench, 2000). Ethiopia possesses the largest donkey population in the world with 8,439,220 donkeys (CSA, 2017; FAO, 2015). Even if, donkey is the least studied species in the country, previously four types of donkeys were recognized; namely Jimma, Abyssinian, Ogaden and Sinnar based on their phenotypic and physical characteristics like average size and coat colour (Befikadu et al., 2015). However, more recent nationwide study identified six distinct domestic donkey populations namely Abyssinian, Afar, Hararghe, Ogaden, Omo and Sinnar (Kefena 2012, Kefena 2014; EBI 2016). The same study showed that, most of the variations in the parameters of morphological 
characteristics vary with eco-geographical patterns and biophysical resources. Therefore, other morphometric variables and corporal indices need to be further incorporated and used to fully characterize and describe donkey populations in Ethiopia (Befikadu et al., 2015). Like all the other regions found within the country, Benishangul Gumuz region possess different donkey phenotypes and their crosses including the country's largest donkey type (Sinnar). Hence this study was aimed at revealing the phenotypic characteristics (qualitative and quantitative parameters) of the different donkey breeds found in the region to be used as input for a further conservation and sustainable utilization of the resources

\section{MATERIALS AND METHODS}

\section{Description of the study areas}

The study was conducted in Benishangul Gumuz Regional State. Benishangul Gumuz Regional State is one of the nine regional states which is located in the western part of Ethiopia between longitude $34^{\circ} 10^{\prime} \mathrm{N}$ and $37^{\circ} 40^{\prime} \mathrm{E}$; and latitude $09^{\circ} 17^{\prime} \mathrm{N}$ and $12^{\circ} 06^{\prime} \mathrm{N}$. It shares border with Amhara Region in the north and north east, South Sudan in the west, Gambella Region in the south, Oromia Region in the south east. The total area of the Region is approximately 50,380 square kilometers with altitude ranging from 580 to 2731 meters above sea level. About $75 \%$ of the Region is low land, $24 \%$ is semi-high land and $1 \%$ is high land. The capital city of the Region is Asossa, located at a distance of 659 kms west of Addis Ababa (Chekol and Getnet, 2010).

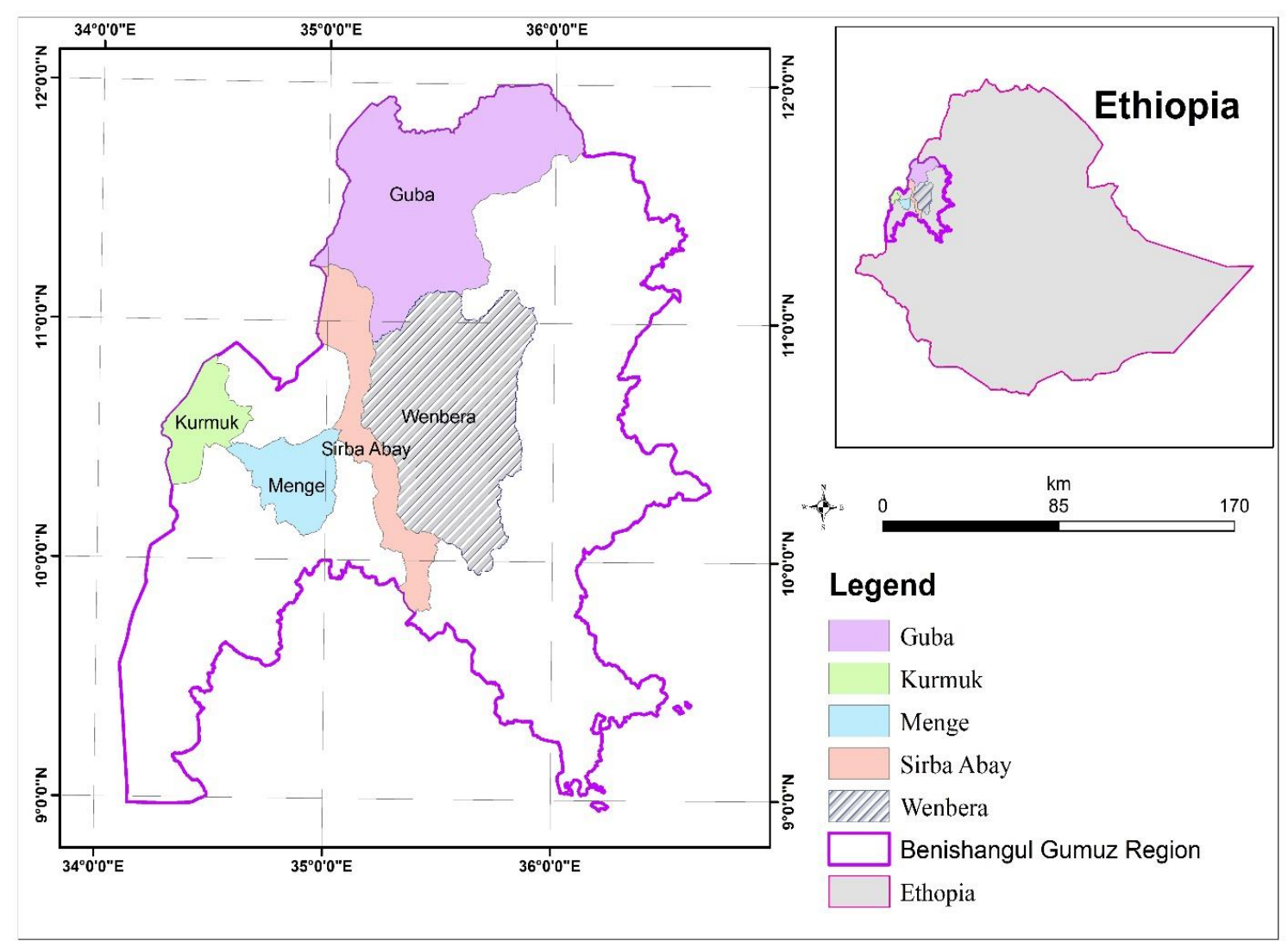

\section{Sampling technique and sample size}

The studied animals (adult donkeys for phenotypic characterization; morphometric and qualitative records) were sampled randomly from five districts (Guba, Menge, Wenbera, Sirba Abay and Kurmuk) within the region. Heterogeneous donkey populations of three phenotypic types (Sinnar, the local donkey and their crossbreds) were used for the qualitative records and morphometric measurements. A total of 323 full-mouthed adult donkeys (123 jacks and 200 jennets) composed of 157 Sinnar, 148 local and 18 crossbred donkeys were measured for linear and circular morphometric traits and described for the qualitative traits.

\section{Measurement and data collection}

The sample size determination and identification of traits for morphometric measurements and qualitative description were based on FAO guideline (FAO, 2012). Fifteen quantitative/ morphometric measurements (Heart girth, Height at wither, Height at back, Height at rump, Body length, Back length, Neck length, Head length, Canon bone length, Fore leg length, Hip width, Chest width, Chest depth, Canon circumference and Ear length) and 18 qualitative characteristics (coat hair size, body color pattern, body (coat) color, abdominal color, head color, ear tip color, tail switch color, hoof color, and muzzle color, ear shape, dorsal stripe, leg stripe, shoulder stripe, face profile, back profile, rump 
profile, tail length and thickness at the base of the tail) were recorded from each individual.

Donkeys were carefully handled by trained laborers and made to stand squarely on flat grounds. Morphometric measurements and qualitative data recording were made by separate individuals. According to a study by Kost'uková (2015), who reported that the growth of donkeys terminates after the age of 5 years and all donkeys in the study were past this age. Body weight was estimated from the above measurements by the formula from Pearson and Ouassat (2000).

Live weight $(\mathrm{kg})=($ heart girth $[\mathrm{cm}] 2.12) \times($ body length $[\mathrm{cm}] 0.688) / 3801$

\section{Table 1 - Sampled number of animals by sex and by breed and proportion of each breeds.}

\begin{tabular}{lcccc} 
Breed /genotype & Jacks & Jennets & Total & Proportion \\
\hline Sinnar & 57 & 100 & 157 & 0.48 \\
Local & 58 & 90 & 148 & 0.46 \\
Crosses & 8 & 10 & 18 & 0.06 \\
Total & 123 & 200 & 323 & 1.00 \\
Proportion & 0.38 & 0.62 & 1.00 & - \\
\hline
\end{tabular}

\section{Statistical analysis}

Data entry and management were done using Microsoft Excel. Analysis of data on quantitative measurements was carried out using the GLM procedure of SAS 9.0 software. Means were compared using Tukey-Kramer (SAS, 2002). Similarly, analysis of qualitative traits was carried out using the non-parametric test (chi-square) procedure of SAS 9.0 software. The model used for the analysis of quantitative data: Yijk $=\mu+A i+B j+C k+$ eijk, where Yijk is an observation, $\mu$ is the overall mean, $\mathrm{Ai}$ is the fixed effect of sex, $\mathrm{Bj}$ is the fixed effect of the breed group, $\mathrm{Ck}$ is the fixed effect of district and eijk is the random error attributed to the nth observation. Interaction effects were found to be non-significant in most cases and were removed from the analysis model.

\section{RESULTS}

\section{Morphometric measurements}

The overall mean, standard error (SE), minimum and maximum value, and coefficients of variation (CV) of the collected morphometric measurements are presented in table 2. For all morphometric traits measured the coefficient of variation was within the range of 5.11 and $\mathbf{8 . 2 7 \%}$. Relatively higher coefficient of variation (13.11\%) was calculated for estimated body weight implying higher variation in terms of body weight. The difference between the minimum and maximum value is sizeable in most cases. A range of $40 \mathrm{~cm}$ for height at wither, $37 \mathrm{~cm}$ for body length, and a range of about $104 \mathrm{~kg}$ for body weight were observed.

Table 2 - Overall least square mean , SE, CV, Minimum and Maximum of body measurements of the donkey populations in Benishangul Gumuz region.

\begin{tabular}{|c|c|c|c|c|}
\hline Traits & Overall Mean \pm SE & Minimum & Maximum & CV (\%) \\
\hline Hearth girth (cm) & $108.7 \pm 0.31$ & 93.0 & 128.0 & 5.18 \\
\hline Height at wither $(\mathrm{cm})$ & $100.2 \pm .030$ & 79.0 & 119.0 & 5.31 \\
\hline Height at back (cm) & $102.0 \pm 0.31$ & 89.0 & 122.0 & 5.41 \\
\hline Height at rump (cm) & $102.3 \pm 0.30$ & 90.0 & 121.0 & 5.22 \\
\hline Body length (cm) & $89.9 \pm 0.30$ & 68.0 & 105.0 & 6.00 \\
\hline Back length (cm) & $67.3 \pm 0.24$ & 57.0 & 86.0 & 6.34 \\
\hline Neck length (cm) & $49.2 \pm 0.23$ & 38.0 & 60.0 & 8.27 \\
\hline Head length $(\mathrm{cm})$ & $42.9 \pm 0.12$ & 36.0 & 50.0 & 5.11 \\
\hline Canon bone length $(\mathrm{cm})$ & $31.4 \pm 0.12$ & 26.0 & 39.0 & 6.92 \\
\hline Fore leg length $(\mathrm{cm})$ & $68.3 \pm 0.26$ & 54.0 & 86.0 & 6.92 \\
\hline Hip width (cm) & $32.6 \pm 0.11$ & 27.0 & 40.0 & 6.60 \\
\hline Chest width (cm) & $22.3 \pm 0.09$ & 18.0 & 29.0 & 7.63 \\
\hline Chest depth (cm) & $49.1 \pm 0.15$ & 42.0 & 59.0 & 5.65 \\
\hline Canon circumference $(\mathrm{cm})$ & $23.7 \pm 0.09$ & 20.0 & 29.0 & 6.70 \\
\hline Ear length (cm) & $23.9 \pm 0.10$ & 19.0 & 28.0 & 7.27 \\
\hline Body weight (kg) & $121.2 \pm 0.93$ & 77.8 & 181.6 & 13.82 \\
\hline
\end{tabular}


Table 3 - Least square means (cm) and pairwise comparison of body measurements with standard error in each

breeds/populations: 1) jakes.

\begin{tabular}{|c|c|c|c|c|}
\hline \multirow{2}{*}{ Traits } & \multicolumn{3}{|c|}{ Breed groups/ phenotypic types } & \multirow{2}{*}{$p$ value } \\
\hline & Sinnar & Local & Cross & \\
\hline $\mathbf{N}$ & 57 & 58 & 8 & \\
\hline Heart girth & $110.4 \pm 0.72^{a}$ & $104.9 \pm 0.71^{b}$ & $107.9 \pm 1.89^{\mathrm{ab}}$ & $\star * *$ \\
\hline Height at wither & $104.0 \pm 0.61^{a}$ & $96.5 \pm 0.60^{b}$ & $101.4 \pm 1.60^{a}$ & $\star * *$ \\
\hline Height at back & $106.5 \pm 0.65^{a}$ & $98.8 \pm 0.64^{b}$ & $103.1 \pm 1.70^{a}$ & $\star * *$ \\
\hline Height at rump & $106.2 \pm 0.67^{a}$ & $98.9 \pm 0.66^{b}$ & $102.3 \pm 1.74^{\mathrm{ab}}$ & $\star * *$ \\
\hline Body length & $90.9 \pm 0.70^{a}$ & $86.2 \pm 0.69^{b}$ & $86.9 \pm 1.82^{a b}$ & $\star * *$ \\
\hline Back length & $67.9 \pm 0.52^{a}$ & $64.7 \pm 0.51^{b}$ & $65.9 \pm 1.36^{\mathrm{ab}}$ & $\star * *$ \\
\hline Neck length & $50.4 \pm 0.53^{a}$ & $46.9 \pm 0.53^{b}$ & $50.1 \pm 1.39^{a b}$ & $\star * *$ \\
\hline Head length & $43.9 \pm 0.27^{a}$ & $42.2 \pm 0.26^{b}$ & $43.7 \pm 0.69^{a b}$ & *** \\
\hline Canon bone length & $33.0 \pm 0.30^{a}$ & $30.8 \pm 0.30^{b}$ & $32.3 \pm 0.78^{\mathrm{ab}}$ & $\star \star *$ \\
\hline Fore leg length & $70.7 \pm 0.59^{a}$ & $66.4 \pm 0.58^{b}$ & $68.1 \pm 1.55^{\mathrm{ab}}$ & $* * *$ \\
\hline Hip width & $32.0 \pm 0.26$ & $31.4 \pm 0.26$ & $31.0 \pm 0.68$ & NS \\
\hline Chest width & $23.0 \pm 0.21^{a}$ & $22.1 \pm 0.20^{b}$ & $22.0 \pm 0.53^{a b}$ & ** \\
\hline Chest depth & $50.1 \pm 0.33^{a}$ & $47.2 \pm 0.33^{b}$ & $49.9 \pm 0.86^{a}$ & $* * *$ \\
\hline Canon circumference & $24.8 \pm 0.21^{\mathrm{a}}$ & $23.9 \pm 0.20^{b}$ & $24.6 \pm 0.54^{a b}$ & * \\
\hline Ear length & $24.0 \pm 0.25^{a}$ & $22.9 \pm 0.24^{b}$ & $25.8 \pm 0.64^{a}$ & ** \\
\hline Body weight & $126.3 \pm 2.14^{a}$ & $108.9 \pm 2.10^{b}$ & $116.4 \pm 5.57^{\mathrm{ab}}$ & $\star * *$ \\
\hline
\end{tabular}

In jacks, with the exception of hip width, donkey phenotypic type had a significant $(\mathrm{P}<0.01)$ effect on the measured traits and it is indicated that almost all body measurements were highest for Sinnar jacks (Table 3) followed by the crossbred type. In almost all cases the difference between the Sinnar and the crossbred jacks is not significant while the difference between the Sinnar and the local is significant in all cases.

The difference between the local and the crosses reached significance level only for height at wither and at back, chest depth and ear length. The Sinnar and crossbred jacks have larger chest depth and taller height at withers than the local jacks. Positive heterosis of more than one percent was calculated for height at withers, neck length, head length, canon bone length, chest depth and ear length. The highest heterosis of close to ten per cent was observed for ear length.

In jennets, significant $(\mathrm{P}<0.05)$ difference was observed between phenotypic types for all morphometric traits (Table 4). In all cases Sinnar jennets along with the crosses have significantly higher values than the local donkeys. No significant difference was observed between Sinnar jennets and the crossbreds. Despite the fact that the crosses would of various types (F1, F2, F3, back cross etc.) and blood levels heterosis of more than one per cent was calculated for body length, fore leg length, hip width, chest width, chest depth, ear length and body weight of jennets.

Table 4 - Least square means $(\mathrm{cm})$ and pairwise comparison of body measurements with standard error in each breeds/populations: 2) jennets.

\begin{tabular}{|c|c|c|c|c|}
\hline \multirow{2}{*}{ Traits } & \multicolumn{3}{|c|}{ Breed groups/phenotypic types } & \multirow{2}{*}{$p$ value } \\
\hline & Sinnar & Local & Cross & \\
\hline $\mathbf{N}$ & 100 & 90 & 10 & \\
\hline Heart girth & $110.8 \pm 0.53 a$ & $107.1 \pm 0.56^{b}$ & $109.8 \pm 1.66^{a b}$ & $\star \star *$ \\
\hline Height at wither & $102.6 \pm 0.6^{a}$ & $97.4 \pm 0.49^{b}$ & $100.7 \pm 1.43^{\mathrm{ab}}$ & $\star * *$ \\
\hline Height at back & $104.3 \pm 0.46^{a}$ & $98.9 \pm 0.49^{b}$ & $101.3 \pm 1.43^{\mathrm{ab}}$ & *** \\
\hline Height at rump & $104.7 \pm 0.44 a$ & $99.6 \pm 0.47^{b}$ & $102.4 \pm 1.39 \mathrm{ab}$ & $* * *$ \\
\hline Body length & $92.4 \pm 0.50 a$ & $89.7 \pm 0.53^{b}$ & $92.0 \pm 1.56^{\mathrm{ab}}$ & ** \\
\hline Back length & $69.0 \pm 0.42^{a}$ & $66.8 \pm 0.45^{b}$ & $66.2 \pm 1.32^{\mathrm{ab}}$ & $\star *$ \\
\hline Neck length & $50.7 \pm 0.39^{a}$ & $48.6 \pm 0.42^{b}$ & $48.9 \pm 1.22^{\mathrm{ab}}$ & ** \\
\hline Head length & $43.7 \pm 0.20^{a}$ & $41.8 \pm 0.21^{b}$ & $43.2 \pm 0.62^{a b}$ & $\star \star *$ \\
\hline Canon bone length & $32.1 \pm 0.18^{a}$ & $30.4 \pm 0.20^{b}$ & $31.4 \pm 0.58^{a b}$ & $\star \star *$ \\
\hline Fore leg length & $70.1 \pm 0.42^{a}$ & $66.8 \pm 0.45^{b}$ & $69.2 \pm 1.33^{a b}$ & $* * *$ \\
\hline Hip width & $33.6 \pm 0.21^{a}$ & $32.5 \pm 0.23^{b}$ & $33.4 \pm 0.67^{a b}$ & $* *$ \\
\hline Chest width & $22.6 \pm 0.17^{a}$ & $21.6 \pm 0.19^{b}$ & $22.6 \pm 0.54^{a b}$ & $\star *$ \\
\hline Chest depth & $50.2 \pm 0.26$ & $48.2 \pm 0.28^{b}$ & $50.1 \pm 0.82^{a b}$ & $\star * *$ \\
\hline Canon circumference & $23.6 \pm 0.15^{a}$ & $23.0 \pm 0.16^{b}$ & $22.9 \pm 0.47 \mathrm{ab}$ & * \\
\hline Ear length & $24.6 \pm 0.16$ & $23.7 \pm 0.17^{b}$ & $24.4 \pm 0.50^{a b}$ & ** \\
\hline Body weight & $128.6 \pm 1.54^{a}$ & $117.1 \pm 1.64^{b}$ & $125.5 \pm 4.83^{\mathrm{ab}}$ & $\star \star *$ \\
\hline
\end{tabular}


The combined data analysis has revealed that there is significant difference between the phenotypic types for all traits and Sinnar donkeys were superior in all cases but the differences between Sinnar and the crosses in some cases was not significant (Table 5). Sinnar donkeys and their crosses have significantly higher $(P<0.05)$ chest depth, ear length, canon bone length and height at withers. The three types were significantly different from each other for height at back and rump. Positive heterosis as calculated from the combined data was found to be more than one per cent for head length, canon bone length, chest depth and ear length. The highest (4.22\%) was calculated for ear length.

Comparison of jacks and jennets have shown that for some of the morphometric variables there is sexual size dimorphism where either the jack or jennet could show higher values as compared to the other sex (Table 6). Jacks have shown significantly $(P<0.05)$ higher values for height at back, cannon bone length, chest width and cannon bone circumference while jennets have significantly higher values for body length, back length, hip width, ear length and body weight. There was no significant $(P>0.05)$ difference between the sexes for heart girth, height at withers, height at rump, neck length, head length, fore leg length and chest depth.

The donkeys were sampled from five locations / districts to consider if there are environmental differences; however, location effects were limited to few of the recorded traits. Body length, back length, neck length, head length, fore leg length and ear length are the traits which have shown significant $(P<0.05)$ fluctuations as the sampling location /district differs. Based on this, foreleg length of donkeys from Wenbera district and head length of donkeys from Sirba Abay district were the shortest among the donkey populations from the other districts. More or less, the results show measurements of donkey populations from Guba district were comparably the largest showing above mean performances.

Table 5 - Least square means (cm) and pairwise comparison of body measurements with standard error in each breeds/populations: 3 ) all sexes.

\begin{tabular}{|c|c|c|c|c|}
\hline \multirow[b]{2}{*}{ Traits } & \multicolumn{3}{|c|}{ Breed groups/ phenotypic types } & \multirow[b]{2}{*}{$p$ value } \\
\hline & Sinnar & Local & Cross & \\
\hline $\mathbf{N}$ & 157 & 148 & 18 & \\
\hline Heart girth & $110.6 \pm 0.44^{a}$ & $106.2 \pm 0.45^{b}$ & $108.9 \pm 1.25^{\mathrm{ab}}$ & *** \\
\hline Height at wither & $103.2 \pm 0.37^{a}$ & $97.1 \pm 0.38^{b}$ & $101.0 \pm 1.07^{a}$ & $* * *$ \\
\hline Height at back & $105.3 \pm 0.38^{a}$ & $98.9 \pm 0.39 c$ & $102.2 \pm 1.10^{b}$ & $* * *$ \\
\hline Height at rump & $105.3 \pm 0.38^{a}$ & $99.4 \pm 0.39 c$ & $102.4 \pm 1.09^{b}$ & $* * *$ \\
\hline Body length & $91.5 \pm 0.41^{a}$ & $88.0 \pm 0.43^{b}$ & $89.7 \pm 1.19^{a b}$ & *** \\
\hline Back length & $68.5 \pm 0.33^{a}$ & $65.9 \pm 0.34^{b}$ & $65.9 \pm 0.96^{b}$ & $* * *$ \\
\hline Neck length & $50.5 \pm 0.32^{a}$ & $47.8 \pm 0.33^{b}$ & $49.4 \pm 0.91^{\mathrm{ab}}$ & *** \\
\hline Head length & $43.9 \pm 0.16^{a}$ & $42.0 \pm 0.16^{b}$ & $43.5 \pm 0.46^{a}$ & *** \\
\hline Canon bone length & $32.5 \pm 0.16^{a}$ & $30.6 \pm 0.17^{b}$ & $31.9 \pm 0.47^{a}$ & *** \\
\hline Fore leg length & $70.3 \pm 0.35^{a}$ & $66.7 \pm 0.36^{b}$ & $68.8 \pm 1.04^{\mathrm{ab}}$ & $* * *$ \\
\hline Hip width & $32.8 \pm 0.17^{a}$ & $31.9 \pm 0.17^{b}$ & $32.3 \pm 0.48^{a b}$ & $\star *$ \\
\hline Chest width & $22.8 \pm 0.14^{a}$ & $21.9 \pm 0.14^{b}$ & $22.4 \pm 0.39 a b$ & *** \\
\hline Chest depth & $50.2 \pm 0.21^{a}$ & $47.8 \pm 0.22^{b}$ & $50.0 \pm 0.60^{a}$ & *** \\
\hline Canon circumference & $24.2 \pm 0.12^{a}$ & $23.5 \pm 0.13^{b}$ & $23.7 \pm 0.35^{a b}$ & ** \\
\hline Ear length & $24.3 \pm 0.14^{a}$ & $23.4 \pm 0.14^{b}$ & $24.8 \pm 0.39 a$ & $* * *$ \\
\hline Body weight & $127.3 \pm 1.28$ & $113.4 \pm 1.31^{b}$ & $121.1 \pm 3.67^{a b}$ & $\star \star \star *$ \\
\hline
\end{tabular}

Table 6 - Least square means and pairwise comparison of body measurements with standard error in each sexes.

\begin{tabular}{|c|c|c|c|}
\hline \multirow{2}{*}{ Body variables } & \multicolumn{2}{|c|}{ Sex } & \multirow{2}{*}{$p$ value } \\
\hline & Jacks & Jennets & \\
\hline $\mathbf{N}$ & 123 & 200 & \\
\hline Heart girth & $108.2 \pm 0.59$ & $108.9 \pm 0.53$ & NS \\
\hline Height at wither & $100.7 \pm 0.51$ & $100.1 \pm 0.46$ & NS \\
\hline Height at back & $102.9 \pm 0.52$ & $101.4 \pm 0.47$ & ** \\
\hline Height at rump & $102.7 \pm 0.51$ & $102.1 \pm 0.46$ & NS \\
\hline Body length & $88.5 \pm 0.56$ & $90.9 \pm 0.51$ & $\star \star * *$ \\
\hline Back length & $66.2 \pm 0.45$ & $67.4 \pm 0.41$ & $\star *$ \\
\hline Neck length & $48.9 \pm 0.43$ & $49.6 \pm 0.39$ & NS \\
\hline Head length & $43.3 \pm 0.22$ & $42.9 \pm 0.20$ & NS \\
\hline Canon bone length & $32.0 \pm 0.22$ & $31.3 \pm 0.20$ & ** \\
\hline Fore leg length & $68.7 \pm 0.48$ & $68.5 \pm 0.43$ & NS \\
\hline Hip width & $31.7 \pm 0.23$ & $33.0 \pm 0.21$ & $\star \star \star *$ \\
\hline Chest width & $22.6 \pm 0.18$ & $22.1 \pm 0.17$ & $\star \star$ \\
\hline Chest depth & $49.2 \pm 0.28$ & $49.5 \pm 0.26$ & NS \\
\hline Canon circumference & $24.4 \pm 0.17$ & $23.2 \pm 0.15$ & $\star \star \star *$ \\
\hline Ear length & $23.9 \pm 0.19$ & $24.4 \pm 0.17$ & ** \\
\hline Body weight & $118.7 \pm 1.73$ & $122.5 \pm 1.56$ & * \\
\hline
\end{tabular}


Table 7 - Least square means (cm) and pairwise comparison of body measurements with standard error in each districts.

\begin{tabular}{|c|c|c|c|c|c|c|}
\hline \multirow{2}{*}{ Traits } & \multicolumn{5}{|c|}{ Sampled Location / District } & \multirow{2}{*}{$p$ value } \\
\hline & Guba & Menge & Wenbera & Sirba Abay & Kurmuk & \\
\hline $\mathbf{N}$ & 58 & 84 & 89 & 59 & 33 & \\
\hline Heart girth & $108.7 \pm 0.81$ & $108.8 \pm 0.64$ & $108.5 \pm 0.68$ & $109.7 \pm 0.77$ & $107.1 \pm 0.97$ & NS \\
\hline Height at wither & $100.2 \pm 0.69$ & $100.4 \pm 0.55$ & $99.9 \pm 0.58$ & $101.8 \pm 0.66$ & $99.8 \pm 0.83$ & NS \\
\hline Height at back & $101.9 \pm 0.71$ & $101.7 \pm 0.56$ & $101.9 \pm 0.59$ & $102.8 \pm 0.68$ & $102.4 \pm 0.86$ & NS \\
\hline Height at rump & $102.7 \pm 0.70$ & $102.1 \pm 0.56$ & $101.8 \pm 0.59$ & $103.1 \pm 0.67$ & $102.1 \pm 0.85$ & NS \\
\hline Body length & $89.0 \pm 0.77 \mathrm{ab}$ & $89.8 \pm 0.61^{a b}$ & $88.5 \pm 0.64^{b}$ & $91.3 \pm 0.73^{a}$ & $90.0 \pm 0.93^{a b}$ & $\star$ \\
\hline Back length & $66.8 \pm 0.62^{a b}$ & $66.4 \pm 0.49^{b}$ & $66.4 \pm 0.52^{b}$ & $68.4 \pm 0.59^{a}$ & $65.9 \pm 0.74^{b}$ & * \\
\hline Neck length & $49.8 \pm 0.59 a b$ & $48.1 \pm 0.47^{b}$ & $49.0 \pm 0.49 a b$ & $49.9 \pm 0.56^{a}$ & $49.3 \pm 0.71^{\mathrm{ab}}$ & * \\
\hline Head length & $43.3 \pm 0.30^{a}$ & $43.6 \pm 0.24^{a}$ & $43.0 \pm 0.25^{a}$ & $41.9 \pm 0.28^{b}$ & $43.7 \pm 0.36$ & $\star * *$ \\
\hline Canon bone length & $31.8 \pm 0.30$ & $31.2 \pm 0.24$ & $31.5 \pm 0.25$ & $31.7 \pm 0.29$ & $32.1 \pm 0.36$ & NS \\
\hline Fore leg length & $69.5 \pm 0.65^{a}$ & $69.1 \pm 0.52^{a}$ & $66.1 \pm 0.55^{b}$ & $69.2 \pm 0.62^{a}$ & $69.1 \pm 0.79 a$ & *** \\
\hline Hip width & $32.5 \pm 0.31$ & $32.6 \pm 0.25$ & $32.5 \pm 0.26$ & $31.6 \pm 0.30$ & $32.5 \pm 0.37$ & NS \\
\hline Chest width & $22.7 \pm 0.25$ & $22.5 \pm 0.20$ & $21.9 \pm 0.21$ & $22.3 \pm 0.24$ & $22.3 \pm 0.30$ & NS \\
\hline Chest depth & $49.0 \pm 0.39$ & $49.9 \pm 0.31$ & $49.2 \pm 0.32$ & $48.9 \pm 0.37$ & $49.5 \pm 0.47$ & NS \\
\hline Canon circumference & $23.7 \pm 0.23$ & $23.9 \pm 0.18$ & $23.8 \pm 0.19$ & $23.7 \pm 0.22$ & $23.9 \pm 0.27$ & NS \\
\hline Ear length & $24.8 \pm 0.25^{a}$ & $23.8 \pm 0.20^{b}$ & $23.9 \pm 0.21^{b}$ & $24.3 \pm 0.24 \mathrm{ab}$ & $23.9 \pm 0.31^{a b}$ & ** \\
\hline Body weight & $120.2 \pm 2.48$ & $121.1 \pm 1.88$ & $119.4 \pm 1.98$ & $124.8 \pm 2.25$ & $117.5 \pm 2.85$ & NS \\
\hline
\end{tabular}

\section{Qualitative characteristics}

The qualitative characteristics of the studied donkey population under the effect of breed, sex and source of the animals is presented in Table 8 and 9. Genotype and environmental factors like sex, animal source and district affects the qualitative characteristics of the studied donkeys. The donkey populations studied possess the following qualitative characteristics; white abdominal color, unpigmented hoof and muzzle, short and medium hair coat cover, plain body color pattern with long dorsal stripe (leg stripe in some cases), straight face and sloppy rump profile, medium tail length and thickness at the base of the tail. The studied qualitative characteristics were affected by different genetic and environmental factors. Breed group has a significant effect on the studied traits except on coat description, abdominal color, face profile and tail length while sex affects few of the qualitative characteristics recorded like coat description, back profile and tail thickness at the base. Similarly source of the animal affects most of the traits except body color pattern, ear shape, leg strip and rump profile.

The results showed dorsal body color of the studied donkey populations was affected $(\mathrm{P}<0.05)$ by breed group of the donkeys. Based on this result, dorsal body color of Sinnar donkeys were $18 \%$ brown, $17 \%$ dark brown, $15 \%$ white, $13 \%$ light red, $8 \%$ dark gray, $8 \%$ gray dun and $21 \%$ others. While the locals were $24 \%$ gray dun, $23 \%$ bay dun, $16 \%$ dark gray dun, $13 \%$ gray/roan, $9 \%$ brown and $15 \%$ others. Similarly, the crossbreds were $22 \%$ bay dun, $22 \%$ dark gray dun, $17 \%$ light red, $11 \%$ black, $11 \%$ dark brown and $17 \%$ other colors. The head color of the Sinnar donkeys was $31 \%$ white, $11 \%$ brown, $10 \%$ light red, $10 \%$ dark brown, $9 \%$ black and $29 \%$ others. However, the head color of the local donkeys was $21 \%$ gray dun, $18 \%$ bay dun, $16 \%$ dark gray dun, $14 \%$ gray/roan, $10 \%$ brown and $21 \%$ others. The crossbreds were also $28 \%$ dark gray dun, $17 \%$ bay dun, $17 \%$ white, $11 \%$ light red, $11 \%$ dark brown, $11 \%$ gray/roan and $5 \%$ others in head color. The ear tips color of Sinnar donkeys was $47 \%$ dark brown, $21 \%$ black, $10 \%$ brown, $9 \%$ light red and $13 \%$ others, while the local donkeys were $63 \%$ dark brown, $28 \%$ black and $9 \%$ other colors. Similarly, the crossbreds were $44 \%$ dark brown, $39 \%$ black and $17 \%$ other in colors of their ear tips. The dominant tail switch color of the studied donkeys was black, with dark brown; almost all (89\%) of the crossbreds possess black tail switch color, similarly most (81\%) of the locals tail switch color was black with $16 \%$ dark brown. The results also showed that $60 \%$ of the Sinnar donkeys had black tail switch color with $20 \%$ dark brown and $20 \%$ other colors.

The study revealed that local and cross donkeys possess plain body color pattern while some of the Sinnar donkeys were shaded. Almost 70 percent of the Sinnar donkey breeds ear shape was round edged while most of the local and crossbreds ear was straight edged in shape. Almost all local (93\%) and crossbreds (83\%) possess long dorsal stripe while this feature was observed on half of the Sinnar donkey breeds. $40 \%$ of the local donkeys had leg stipe, however, it was not seen on most of the Sinnar and its crossbred donkeys. Most local donkeys and the crossbreds had either short or long shoulder stripe, while, it was absent on more than half of the Sinnar donkeys. Almost $50 \%$ of the Sinnar donkeys back profile was convex, however, in most of the crossbreds and local donkeys it was hollow.

The results also showed that most of the short coat hair size was possessed by jacks while the jennets had medium coat description. Most of the jacks back profile was hollow while the jennets were hollow. Most of the jacks had small to medium thickness at the base of their tail, however it was medium to large for the jennets. Purchased animals had short coat hair size while the born ones had medium coat description.

There was no dorsal stripe on half of the purchased donkeys while half of them possess long. On the other hand, most of the donkeys born on-farm possess long dorsal stripe. Similarly, there was no shoulder stripe on more than half (52\%) of the purchased donkeys while there was either short or long shoulder stripe for the donkeys born there. Most of the purchased donkeys back profile was convex while half of the borne ones possess hollow back profile. Short and medium tail length was observed on the donkeys born there while the purchased donkeys tail length was medium to long. 
Animals were sampled from different locations/districts to have a representative picture of the study area (Benishangul Gumuz region). Most of the qualitative characteristics of the studied donkey populations were significantly $(P<0.05)$ influenced by location /district. Based on this, ear shape, leg stripe, shoulder stripe, back profile, rump profile, tail length and thickness at the base of the tail are some of the traits which show significant differences among districts. The results show most of the donkeys from Kurmuk district had round edged ear shape while straight edged ear shape was seen on most of the donkeys sampled from Menge district. Most of the donkey populations from the sampled locations do not possess leg stripe while $50 \%$ of the donkeys from Guba and Kurmuk districts had a leg stripe.

The results also revealed that most of the donkeys from Sirba Abay district had a hollow back profile while straight back profile was observed on above half of the donkeys from Guba district. On the other hand, above half of the donkeys from Menge district had convex back profile.

\section{Table 8 - Percentage of qualitative traits in each breed/populations, sexes and animal sources.}

\begin{tabular}{|c|c|c|c|c|c|c|c|}
\hline \multirow{2}{*}{ Traits } & \multicolumn{3}{|c|}{ Breeds/populations } & \multicolumn{2}{|c|}{ Sex } & \multicolumn{2}{|c|}{ Animal source } \\
\hline & Sinnar & Local & Cross & Jacks & Jennets & Born & Purchased \\
\hline $\mathbf{N}$ & 157 & 148 & 18 & 123 & 200 & 232 & 91 \\
\hline Coat hair size (Chi-square) & & NS & & \multicolumn{2}{|c|}{$\star \star *$} & \multicolumn{2}{|r|}{ ** } \\
\hline Short & 48 & 39 & 39 & 63 & 31 & 38 & 57 \\
\hline Medium & 47 & 53 & 61 & 36 & 60 & 55 & 38 \\
\hline Long & 5 & 8 & 0 & 1 & 9 & 7 & 5 \\
\hline Body color pattern (Chi-square) & \multicolumn{3}{|c|}{$\star \star * *$} & \multicolumn{2}{|c|}{ NS } & \multicolumn{2}{|r|}{ NS } \\
\hline Plain & 75 & 100 & 94 & 89 & 87 & 90 & 81 \\
\hline Shaded & 25 & 0 & 6 & 11 & 13 & 10 & 19 \\
\hline Ear shape (Chi-square) & \multicolumn{3}{|c|}{$\star * *$} & \multicolumn{2}{|c|}{ NS } & \multicolumn{2}{|r|}{ NS } \\
\hline Rounded & 69 & 22 & 28 & 48 & 43 & 42 & 53 \\
\hline Straight & 31 & 78 & 72 & 52 & 57 & 58 & 47 \\
\hline Dorsal strip (Chi-square) & \multicolumn{3}{|c|}{$* * *$} & \multicolumn{2}{|c|}{ NS } & \multicolumn{2}{|r|}{$\star \star \star$} \\
\hline Absent & 50 & 7 & 17 & 29 & 27 & 22 & 45 \\
\hline Long & 49 & 93 & 83 & 70 & 72 & 77 & 55 \\
\hline Short & 1 & 0 & 0 & 1 & 1 & 1 & 0 \\
\hline Leg strip (Chi-square) & \multicolumn{3}{|c|}{ ** } & \multicolumn{2}{|c|}{ NS } & \multicolumn{2}{|r|}{ NS } \\
\hline Present & 19 & 39 & 17 & 29 & 27 & 30 & 22 \\
\hline Absent & 81 & 61 & 83 & 71 & 73 & 70 & 78 \\
\hline Shoulder stripe (Chi-square) & \multicolumn{3}{|c|}{$\star * *$} & \multicolumn{2}{|c|}{ NS } & \multicolumn{2}{|r|}{$\star * \star$} \\
\hline Absent & 52 & 9 & 17 & 30 & 31 & 22 & 52 \\
\hline Long & 21 & 46 & 44 & 32 & 35 & 39 & 21 \\
\hline Short & 27 & 45 & 39 & 38 & 34 & 39 & 27 \\
\hline Face profile (Chi-square) & \multicolumn{3}{|c|}{ NS } & \multicolumn{2}{|c|}{ NS } & & * \\
\hline Convex & 27 & 38 & 33 & 36 & 31 & 37 & 22 \\
\hline Straight & 72 & 61 & 67 & 63 & 68 & 62 & 78 \\
\hline Concave & 1 & 1 & 0 & 1 & 1 & 1 & 0 \\
\hline Back profile (Chi-square) & & $\star \star$ & & & $r$ & & $* \star$ \\
\hline Hollow & 32 & 47 & 61 & 32 & 45 & 47 & 24 \\
\hline Straight & 19 & 23 & 0 & 20 & 20 & 20 & 19 \\
\hline Convex & 49 & 30 & 39 & 48 & 35 & 33 & 57 \\
\hline Ramp profile (Chi-square) & & ** & & & $\mathbf{S}$ & & NS \\
\hline Flat & 22 & 36 & 39 & 37 & 25 & 33 & 22 \\
\hline Sloppy & 65 & 59 & 61 & 56 & 65 & 59 & 68 \\
\hline Roofy & 13 & 5 & 0 & 7 & 10 & 8 & 10 \\
\hline Tail length (Chi-square) & & NS & & & 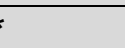 & & * \\
\hline Short & 25 & 30 & 33 & 26 & 30 & 32 & 18 \\
\hline Medium & 50 & 40 & 22 & 37 & 48 & 43 & 46 \\
\hline Long & 25 & 30 & 45 & 37 & 22 & 25 & 36 \\
\hline Tail base thickness (Chi-square) & & * & & & $*$ & & * \\
\hline Narrow & 33 & 17 & 17 & 34 & 19 & 20 & 36 \\
\hline Medium & 44 & 56 & 55 & 59 & 45 & 53 & 44 \\
\hline Wide & 23 & 27 & 28 & 7 & 36 & 27 & 20 \\
\hline
\end{tabular}


Table 9 - Percentage of qualitative traits in each districts.

\begin{tabular}{|c|c|c|c|c|c|c|}
\hline \multirow{2}{*}{ Traits } & \multicolumn{6}{|c|}{ Location / district } \\
\hline & Guba & Menge & Wenbera & Sirba Abay & Kurmuk & Chi-square \\
\hline $\mathbf{N}$ & 58 & 84 & 89 & 59 & 33 & \\
\hline Coat hair size & & & & & & NS \\
\hline Short & 53 & 39 & 43 & 44 & 39 & \\
\hline Medium & 40 & 54 & 50 & 51 & 61 & \\
\hline Long & 7 & 7 & 7 & 5 & 0 & \\
\hline Body color pattern & & & & & & NS \\
\hline Plain & 84 & 90 & 89 & 83 & 91 & \\
\hline Shaded & 16 & 10 & 11 & 17 & 9 & \\
\hline Ear shape & & & & & & *** \\
\hline Rounded & 43 & 26 & 52 & 47 & 73 & \\
\hline Straight & 57 & 74 & 48 & 53 & 27 & \\
\hline Dorsal strip & & & & & & NS \\
\hline Absent & 26 & 32 & 34 & 17 & 27 & \\
\hline Long & 74 & 68 & 64 & 83 & 73 & \\
\hline Short & 0 & 0 & 2 & 0 & 0 & \\
\hline Leg strip & & & & & & $\star * *$ \\
\hline Present & 43 & 27 & 11 & 31 & 42 & \\
\hline Absent & 57 & 73 & 89 & 69 & 58 & \\
\hline Shoulder stripe & & & & & & ** \\
\hline Absent & 33 & 35 & 35 & 15 & 30 & \\
\hline Long & 22 & 39 & 25 & 56 & 27 & \\
\hline Short & 45 & 26 & 40 & 29 & 42 & \\
\hline Face profile & & & & & & ** \\
\hline Convex & 26 & 27 & 48 & 20 & 39 & \\
\hline Straight & 74 & 70 & 52 & 80 & 61 & \\
\hline Concave & 0 & 3 & 0 & 0 & 0 & \\
\hline Back profile & & & & & & *** \\
\hline Hollow & 16 & 30 & 40 & 76 & 45 & \\
\hline Straight & 55 & 13 & 24 & 0 & 0 & \\
\hline Convex & 29 & 57 & 36 & 24 & 56 & \\
\hline Ramp profile & & & & & & ** \\
\hline Flat & 21 & 32 & 27 & 42 & 24 & \\
\hline Sloppy & 77 & 55 & 66 & 54 & 55 & \\
\hline Roofy & 2 & 13 & 7 & 4 & 21 & \\
\hline Tail length & & & & & & $* * *$ \\
\hline Short & 21 & 11 & 29 & 44 & 55 & \\
\hline Medium & 45 & 55 & 38 & 37 & 39 & \\
\hline Long & 34 & 34 & 33 & 19 & 6 & \\
\hline Tail base thickness & & & & & & $* * *$ \\
\hline Narrow & 31 & 36 & 21 & 3 & 33 & \\
\hline Medium & 48 & 44 & 59 & 49 & 49 & \\
\hline Wide & 21 & 20 & 20 & 48 & 18 & \\
\hline
\end{tabular}

\section{DISCUSSION}

\section{Effect of breed group}

The results revealed that there were differences among the studied breeds/populations indicating Sinnar donkeys were significantly bigger than the local donkeys while some similarities were observed with the crosses which might be due to heterosis effect. Heterosis of various magnitude was calculated for the various traits studied. However, as the crosses are of diverse type (F1, F2, back cross etc.) and blood level it will be difficult to interprete the heterosis effect obtained in this study in both sexes. The big body size, height and length in the measured traits of Sinnar indicated that the breed is highly adaptable to the hot environment with good reproduction ability (Beja-Pereira et al., 2004; Marshall 2007; Rossel et al., 2008). These results are in line with the results of Kefena et al., (2011) and Tsega and Lemma (2015) who reported Sinnar donkeys are the tallest of all donkey populations in Ethiopia and they are also an excellent desert adapted animals used for riding and breeding. Therefore, due to these special characteristics of the Sinnar donkey, Kefena et al. (2011) has reported that its ancestral trunk might be different from the rest of the donkey breeds/populations but this needs to be supported by further genetic studies. Some of the characteristics of desert adapted donkeys include fairly bigger body sizes and similarities in coat color patterns among donkey populations of arid and semi-arid lowlands (Beja-Pereira et al., 2004; Marshall, 2007; Rossel et al., 2008). Differences in breed groups in this study were in line with the results of Kostuková et al. (2015). The possible cause of differences among the studied breed groups might be due to the differences in domesticated ancestors, ecology and biophysical resources for the overall body build and local environment and history (Beja-Pereira et al., 2004; Kefena et al., 2014; Gubitz et al., 2000). The local breeds were smaller and lighter than the Sinnar donkeys which is suitable for different purposes which is in line with the 
results of Sargentini et al. (2018) who reported that the Amiata donkeys' biometrics (small-medium sized) was suitable for different purposes.

The dominant body colors of Sinnar donkeys from this study were white and light colors with short to medium hair while, most of the locals and crossbreds possess gray dun and bay dun with medium hair size. These results are in line with the results of study by Tsega and Lemma (2015) in Gondar, Ethiopia, who reported Sinnar donkeys possess white body color with short hair and crossing them with Abyssinian donkeys often results in hairier, longer, saggy and dark colored hybrids.

\section{Effect of sex}

Eight of the fifteen morphometric measurements were significantly affected by sex; jacks were dominant over the jennets in four traits (height at back, chest width, canon bone length and canon circumference) while the jennets were dominant over jacks in five traits (body length, back length, ear length, hip width and body weight). These results were in line with the results of Kost'uková et al., (2015) and partially with the results of Folch and Jordana (1997) on Catalonian donkeys. The magnitude of sexual dimorphism in the current study is quite higher than what has been reported for Catalonian donkeys where only Eight out of twenty-six morphometric measurements showed significant differences between sexes (Folch and Jordana, 1997). The report of Koubek (1933) also showed that male donkeys have lower heart girth and stronger shin than the jennets. Jacks in this study were stronger (wide chest and thick canon) than the jennets which is in line with the results of Andersson (1994 cit. in Purzyc et al., 2007) who reported that, there are specific physiological and biochemical processes in jacks, which results in them being stronger than the jennets. In line with the current study the chest circumference and hip width in female individuals is mainly influenced by physiological processes during gestation and by metabolic traits that differ from those in males (Koubek, 1933). Similarly, height at wither and at rump were not significantly different among the sexes while the jennets had shorter height at back than the jacks which might be due to the fetus load which pull their belly down during the pregnancy period. On the other hand, it might also be due to their loss of strength to hold up the load they carry in comparison to jacks.

\section{Effect of location}

Location affects only six traits (body, back, head, neck, ear and fore leg length) out of the eighteen morphometric measurements. In the study by Tsega and Lemma (2015) on Sinnar donkeys in Gondar, Ethiopia, differences in morphometric measurements and qualitative characteristics were recorded among different sampling location due to differences in ecological selection regimes, history or both. However, such huge significant differences were not recorded in the present study which may be due to the closeness of the locations sampled. However also, the donkeys from the locations/ districts which are on the border with South Sudan shows some dominance over the others as these districts may serve as the gate ways of the Sinnar donkeys to the region. Most of the qualitative characteristics of the purchased donkeys approaches the characteristics of Sinnar donkeys, showing most of the farmers were purchasing Sinnar donkeys preferring their heaviness. The white color and short hair size of the Sinnar donkeys might help them in physiological adaptation of the hot environments.

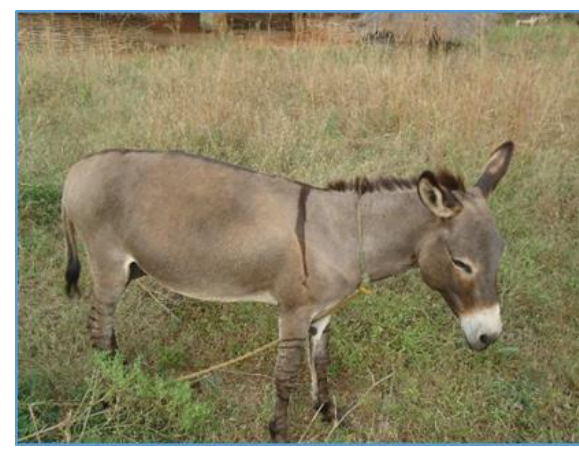

Local Male

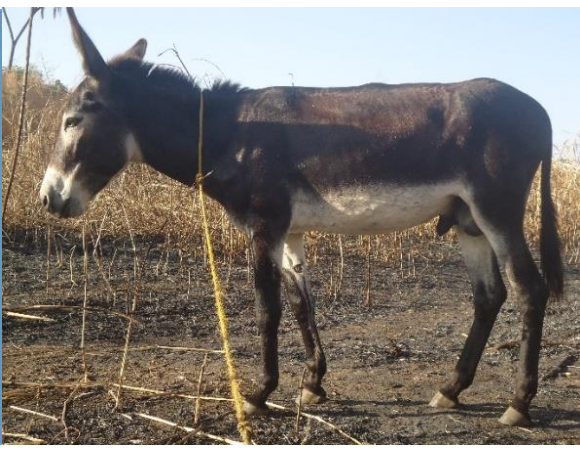

Sinnar Male

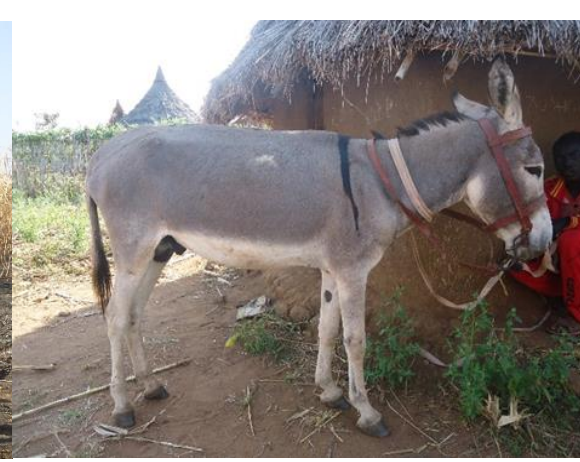

Cross Male

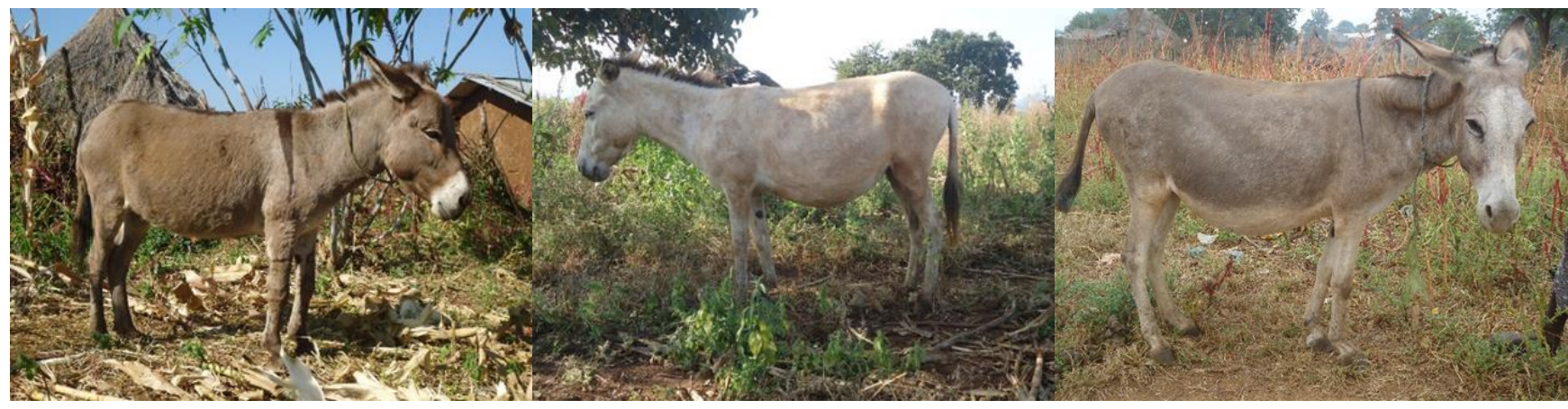

Local Female

Sinnar Female

Cross Female 


\section{CONCLUSION}

The donkeys in Benishangul Gumuz region were characterized based on FAO guidelines. Accordingly, three phenotypic types were covered; the Sinnar, the locals and their crossbreds. Significant differences were recorded among the three breed groups on the studied morphometric measurements and qualitative characteristics. Based on these results the Sinnar donkeys were the tallest, widest and strongest with some similarities with their crosses. Some sex effect was observed on the overall performances while, its effect was limited on the interaction effect with the breed groups. However, jacks and jennets were dominating each other on equal basis. Jacks had wide chest, thick canon and long height at rump and cannon bone, while the jennets possess wide hip and long body, back, neck and ear. Significant differences were observed between sampled location for some of the studied traits. Qualitative differences were also recorded among the studied class categories. Further molecular level studies are required to characterize the differences among the studied donkey breed groups. Similarly, characterization of the local donkeys found in other parts of the region and the Abyssinian donkeys in adjoining areas is required.

\section{DECLARATIONS}

\section{Corresponding Author}

E-mail: aminemustefa32@gmail.com; ORCID: 0000-0003-3788-4156

\section{Acknowledgements}

The authors are highly indebted to the animal owners as without their permission the completion of this work would not have been possible. Our special appreciation also goes to the head and staff of Ethiopian Biodiversity Institute (especially Animal Biodiversity Directorate), and the district agricultural offices found in the study area who actively participated during the data collection process.

\section{Authors' Contribution}

AM contribute on data analysis and the write up of the manuscript, AA, MM, FG conceived the study and collect data, SA review the manuscript, $A H$ and $Y E$ contribute on entering data. All authors read and approved the final manuscript.

\section{Funding}

This research was funded by the Ethiopian biodiversity institute.

\section{Conflict of interests}

The authors have not declared any conflict of interests.

\section{REFERENCES}

Befikadu Z, Kiflay W and Sanjoy KP (2015) Conservation of Indigenous Donkey Breeds of Ethiopia: A Review. International Journal of Interdisciplinary and Multidisciplinary Studies, 2 (6): 13-22.

Beja-Pereira A, England P R, Ferrand N, Jordan S, Bakhiet A O, Abdalla M A, Mashkour M, Jordana J, Taberlet P and Luikart G (2004) African origin of domestic donkey. Science, 304: 1781

Blench RM (2000) A history of donkeys, wild asses and mules in Africa. In: Blench, Roger M., MacDonald, Kevin C. (Eds.) The origin and development of African livestock: archaeology, genetics, linguistics and ethnography. UCL Press, pp. 339-354.

Chekol K and Getnet A (2010) Public Finance Review: Benishangul-Gumuz Regional State Pp. 83

CSA (Central Statistical Agency) (2017) Agricultural sample survey 2016/2017. Report on livestock and livestock characteristics. Addis Ababa, Ethiopia. pp. 188

EBI (Ethiopian Biodiversity Institute) (2016) Ethiopian National Strategy and Plan of Action for conservation and utilization of Animal Genetic Resources, Addis Ababa, Ethiopia. Pp. 114

FAO (Food and Agricultural Organization of the United Nations) (2015) In: Scherf B. \& Pilling D. (Eds.), The second report on the state of world's: animal genetic resources for food and agriculture. FAO, Rome, Italy.

FAO (Food and Agricultural Organization of the United Nations) (2012) Phenotypic characterization of animal genetic resources. Food and Agriculture Organization of United Nations. Rome, Italia. Animal Production and Health Guidelines 11, 144.

Folch P and Jordana J (1997) Characterization, reference ranges and the influence of gender on morphological parameters of the endangered Catalonian donkey breed. Journal of Equine Veterinary Science, 17 (2): 102-111.

Gubitz T, Thorpe R S and Malhotra A (2000) Phylo-geographic and natural selection in the Tenerife gecko Tarentoal delalandii: testing historical and adaptive hypothesis. Molecular Ecology, 9: 1213-1221.

Kefena E, Beja-Pereira A, Han JL, Haile A, Mohammed YK and Dessie T (2011) Eco-geographical structuring and morphological diversities in Ethiopian donkey populations. Livestock Science 141, 232-241 http://dx.doi.org/10.1016/j.livsci.2011.06.011 
Kefena E, Dessie T, Tegegne A, Beja-Pereira A, Yusuf Kurtu M, Rosenbom S and Han JL (2014) Genetic diversity and matrilineal genetic signature of native Ethiopian donkeys (Equus asinus) inferred from mitochondrial DNA sequence polymorphism. Livestock Science, http://dx.doi.org/10.1016/j.livsci.2014.06.006

Kefena E (2012) Equine genetic resources of Ethiopia. PhD. dissertation Haramaya University, Dire Dawa. Ethiopia.

Kostúuková M, Černohorská H, Bihuncová I, Oravcová I, Sobotková E and Jiskrová I (2015) Characteristics of morphological parameters of donkeys in the czech republic. acta universitatis agriculturae et silviculturae mendelianae brunensis, 63 (2): 419-424 http://dx.doi.org/10.11118/actaun201563020419

Koubek K (1933) Speciální zootechnika - Chov koní. Praha: Státní zemědělské nakladatelství Praha.

Marshall F. (2007) African pastoral perspectives on domestication of the donkey: a first synthesis. In: Denham, T., Iriarte, J., Vrydaghs, L. (Eds.), Rethinking Agriculture: Archaeological and Ethnoarchaeological Perspectives. Left Coast Press, Walnut Creek, California, USA.

Pearson R A and Ouassat M (2000) A Guide to Body Condition Scoring and Live Weight Estimation of Donkeys. Centre for Tropical Veterinary Medicine, University of Edinburgh, p. 21

Purzyc H, Kobryn H, Komosa M and Bojarski J (2007) Ocena eksterieru konia huculskiego na podstawie wybranych wskaźników morfometrycznych (część i). Acta Scientarum Polonorum - Medicina Veterinaria, 6: 47-64.

Rossel S, Marshall F, Peters J, Pilgram T, Adams M D and O'Connor D. (2008) Domestication of the donkey: timing, processes and indicators. Proceedings of the National Academy of Sciences of the United States of America, 105: 3715-3720.

Sargentini C, Tocci R, Martini A and Bozzi R (2018) Morphological characterization of Amiata donkey through Multivariate analyses. Revista Brasileira de Zootecnia, 47: e20170310, https://doi.org/10.1590/rbz4720170310

SAS (Statistical Analysis System). (2002) Institute Inc., Cary, NC, USA.

Tsega A and Lemma A (2015) Phenotypic characteristics and sexual behavior of Sennar Jacks (Equus asinus). Ethiopian Veterinary Journal, 19 (1): 11 - 21. 